\title{
Structural Equation Modeling for Studying Adaptation of the Students with Disabilities in Inclusive Junior High Schools
}

\author{
Li Ju Chen ${ }^{1 *}$ \\ ${ }^{1}$ Graduate Institute of Early Intervention, Chang Gung University, Taiwan \\ *Correspondence: Graduate Institute of Early Intervention, Chang Gung University, 259 Wen-Hua $1^{\text {st }}$ Road \\ Kwei-Shan, TaoYuan, 33302, Taiwan. Tel: 886-3-211-8800\#5530. E-mail: lizzy8989@gmail.com
}

Received: November 7, 2013

Accepted: December 27, 2013 Online Published: January 7, 2014

doi:10.5430/wje.v4n1p11

URL: http://dx.doi.org/10.5430/wje.v4n1p11

\begin{abstract}
This research explored the factors of the adaptation for the children with disabilities studying in inclusive junior high schools. The subjects were recruited from the Special Needs Education Longitudinal Study of Taiwan. The result of the Confirmatory Factor Analyses reflects that there are two, three and five observed variables included in the intervention timing, language skills, and school adaptation respectively. Per structural equation modeling, the research found that the intervention timing impacts the children' language skills, and language skills impact the children's adaptation in inclusive junior high school setting. Based on the research findings, some implications for intervention practices are provided.
\end{abstract}

Keywords: inclusive education setting; language skill; outcome-based intervention; structural equation modeling; students with disabilities

\section{Introduction}

In the 1990's, the federal government of the United States emphasized the accountability of federal programs and the need to achieve evidence-based effectiveness, and it required each program's effectiveness be evaluated (Baughman et al., 2010; Rabren \& Johnson, 2010). Under this outcome-based evaluation policy, the federal government required the related departments to submit the outcomes of early intervention and special education programs (Kasprzak \& Rooney, 2008). Some departments, such as the Early Childhood Outcomes Center (ECOC), were thus created to assess the outcome of special education for infants, young children, and preschool children with disabilities. The assessment reports from these departments were used to reform the ongoing policies or to develop new policies (Baughman et al., 2010). Consequently, there was a growing demand for research exploring the factors affecting the outcomes of intervention (Coutinho, Oswald, \& Best, 2006). The intervention's outcome directly measured from the children's performance is believed to be a realistic indicator of the intervention's effectiveness. Based on such realistic indicators, the ongoing intervention can be improved accordingly.

\subsection{The Effectiveness of Intervention}

Which performances should be selected to represent the outcomes or effectiveness of an intervention? Depending on the time when the outcomes are measured, the effectiveness of an intervention program or policy can be classified as demonstrating short-term, medium-term, or long-term effectiveness (Del Prette, DelPrette, \& De Oliveira, 2012). Short-term effectiveness can is evaluated immediately after the children receive the intervention. However, short-term effectiveness may be either temporary or not certainly related to special education's ultimate goal. The most important goal of special education and early intervention is to help the children with disabilities to be more independent in their daily lives, to contribute more to society, and to blend easily into society and enjoy their lives as other people do (Koegel, Koegel, Frea, \&Fredeen, 2001; Stahmer, Carter, Baker, \& Miwa, 2003). Long-term effectiveness is often expressed in the individual's performance, behavior and ability, and it can be measured some years after the children have entered an inclusive school or society. A Norway's research explored the factors affecting intervention effectiveness by studying the school adaptation of eight-year-old students (NICHD Early Child Care Research Network, 2005). To assess the children's performance of long-term intervention effectiveness, a follow-up evaluation should be conducted several years after the children have enrolled in school. 
Akshoomoff, Stahmer, Corsello and Mahrer (2013) indicated that $63 \%$ of the children with disabilities who had received early intervention entered into schools with inclusive settings. From the database of the Special Needs Education Longitudinal Study of Taiwan (SNELS), $77.7 \%$ of the children with disabilities in Taiwan who had received early intervention entered into an inclusive elementary school (SNELS, 2013). However, the physical integration of students with disabilities into mainstream classrooms does not guarantee true inclusion (Brown, Ouellette-Kuntz, Lysaght, \& Burge, 2011). Oliver (2008) and Rous, Hallam, McCormick, and Cox (2010) indicated that inclusive education is meaningful only if the children have positive outcomes in both their academic and their emotional development. Aron and Loprest (2012) indicated that researchers could neither accurately gauge the efficacy of the intervention services nor formulate effective reforms to the system while the intervention was being delivered. The concept of outcome-based services is that the quality of intervention is not certainly equal to the effectiveness of the intervention. Tracking children's adaptation to school and exploring the impacts on the children's learning and living performance some years after they received intervention can help to effectively modify the content of the intervention.

One of the important developments in childhood is the relationships with peers. The research holds that children with disabilities who adapt well in school and have good social interaction with peers should also adapt better in society and should have better social interaction in the communities in which they live (Koegel et al, 2001; Stahmer et al., 2003). It is claimed that a child with a disability can develop better social behaviors in an inclusive environment than in a segregated environment (Alquraini \& Got, 2012; Koegel et al., 2001). Children's adaptation in schools in an inclusive setting can be used to predict their future adaptation in society and be considered to be an indicator of long-term effectiveness of the intervention. Akshoomoff et al. (2013) indicated that enabling children with disabilities to study in an inclusive environment is a major goal of early intervention. The National Institute for Early Education Research indicated that adequate early intervention enables children with disabilities to enter into elementary schools without needing special education (Council for Exceptional Children, 2003). Del Prette et al. (2012) indicated that children with disabilities who had poor interpersonal relationships with their peers and teachers would likely experience short-, medium-, and long-term difficulties in their educational, psychological, and vocational performance. Children's future performance was anticipated based on their social relationships in school, and thus social relationships may become an indicator of the early intervention's long-term effectiveness. Koegel et al. (2001) and Huang (2003) studied the effectiveness and value of early intervention based on children's interaction with peers, interaction with teachers, and participation in school activities in an inclusive education environment. The direct goal of early intervention is to enable children with disabilities to perform well in interpersonal interaction, daily life activities and academic learning.

\subsection{Factors that Influence Intervention Effectiveness}

The present research explored the factors that affect the adaptation of children with disabilities in inclusive junior high schools and how these factors affect the effectiveness of the intervention. According to the research result, we can improve the intervention system, content, and policies to maximize the intervention's effectiveness. The factors proposed in the past researches can be classified into two types:

\subsubsection{Intervention Timing}

Many studies have explored the ideal timing for an intervention that enables children with disabilities to adapt and learn well in inclusive school settings (Akshoomoff et al., 2013; NICHD Early Child Care Research Network, 2005; Stahmer et al., 2003). Neuman (2007) concluded that the earlier the intervention occurs, the more effective the outcome is. Providing opportunities for early identification and intervention ultimately prevents the development of more severe problems and promotes more positive outcomes (Aron\&Loprest, 2012; Renshaw et al., 2009; Shonkoff $\&$ Meisels, 2002). The conclusion from the research is that the early identification of children's disabilities and timely intervention might affect the intervention's effectiveness. It is important to determine whether the children are being identified in a timely manner and given the most appropriate and effective services.

\subsubsection{Language Skills}

Quick hallway greetings make a person more interactive and more likely to initiate interactions with others. These greetings require the immediate delivery of spoken language (Rossetti, 2011). Akshoomoff et al. (2013) indicated that the school adaptation of a child with a disability is related to his/her communication skills. The importance of language skills explains why the Head Start Program in the 1960s emphasized the improvement of a child's language skills to prevent learning failure in future school.

Research in Norway found that at the age of eight, children with disabilities who received early intervention had 
better language skills than those who did not receive early intervention. (NICHD Early Child Care Research Network, 2005). In summary, both intervention timing and language skills are possible key factors affecting children's school adaptation in an inclusive education environment, and early intervention may impact the children's language skills. In this research, a statistical approach of Structural Equation Modeling (SEM) was used to explore this relationship. In SEM, three hypothetical latent variables - intervention timing, language skills, and school adaptation-were created to develop a structural equation model.

Many researches have studied the effectiveness of interventions based on measuring quantities related to the service, such as time spent, child count, service content, budget, and so on, but these measures do not allow definite conclusions about effectiveness (Aron \& Loprest, 2012). The content, process, or setting of the intervention cannot represent the intervention's effectiveness; only the outcomes of the intervention can represent its effectiveness. The purpose of this research is to use SEM approach to investigate how intervention timing and language skills affect junior high school children' school adaptation. This research intends to help improve early intervention according to its findings and to maximize the efficacy of interventions.

\section{Methods}

\subsection{Research Design}

This research used SEM approach to analyze which factors affect children's school adaptation and how. The researcher first proposed an initial structural model (Figure 1) that consists of three latent variables: intervention timing and language skills as exogenous variables and school adaptation as an endogenous variable. Each latent variable is defined by a number of observed variables, which were initially chosen from SNELS according to the previous literature and then reviewed by 12 professionals. Through Confirmatory Factor Analyses (CFA), the three latent variables were correctly quantified by the observed variables:

\subsubsection{Intervention Timing}

Intervention timing indicated the time of a child begins his/her intervention afforded by at least one professional, included special educator, rehabilitation therapist, or medical treatment professional in order to improve the children's development. The observed variables used to quantify intervention timing are the age at which the child received the first intervention, the age at which the child's disability was first identified, the age at which the child received a disability certificate, and the age at which the child first received special education. The units of these observed data are ages.

\subsubsection{Language Skills}

Language skills indicated the skill of language expression and reception when communicating with others. The observed variables used to quantify language skills are the evaluations by the student's parent on: their child's language expression ability compared with their schoolmates, their child's language comprehension ability compared with their schoolmates, the likelihood of their child's verbal expression being understood by strangers compared with their schoolmates, and their child's willingness to initiate communication with others compared with their schoolmates. The score of each evaluation question ranges from one to four, where one indicated the student's language skills are as good as his/her schoolmate, two the language skills have some problems, three the language skills have big problems, and four the student cannot expression at all.

\subsubsection{School Adaptation}

The observed variables to quantify the school adaptation are the parents' satisfaction with their child's interaction with teachers, interaction with peers, participation in school activities, academic performance, and the parents' overall satisfaction with their child's studies in that school. The score of each question ranges from one to four, where one indicated very satisfied, two satisfied but not so much, three unsatisfied, four very unsatisfied. 


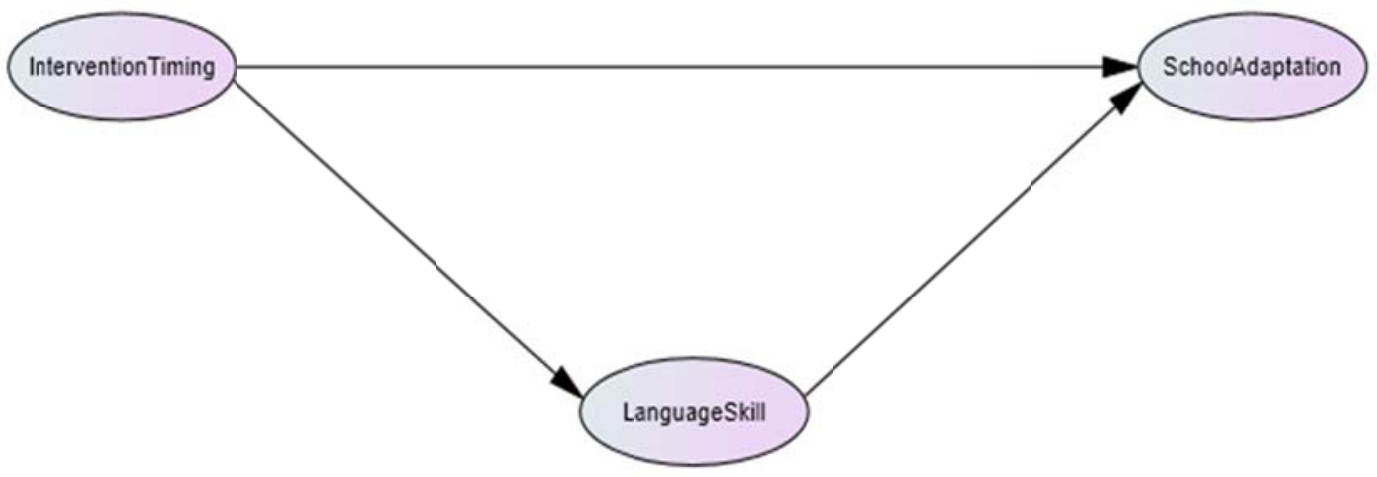

Figure 1: Intervention-inclusion Structural Model

After CFA, only the appropriate observed variables remain in the model. Next, per SEM analysis, the proposed structural model is revised and verified, and the influential links between latent variables are quantified. In the process of model verification, the relationships between the three latent variables are computed. Next, from the final structural model, we can determine how the factor intervention timing affects the children's language skills and school adaptation and how the factor language skills influence school adaptation.

\subsection{Subjects}

The subjects recruited in SNELS were randomly sampled from a list of all the children with disabilities in Taiwan less than nineteen years of age. This list was published in Taiwan Special Education Transmit Net. The data from the recruited subjects includes their family background, personal information, medical records, education records, after school status, etc. The data bank SNELS was established in 2007. From 2007 to 2012, the data bank collected twenty groups of data.

The group data used in this research was established by SNELS in 2009 from a survey conducted with the parents of 3180 junior high school children with disabilities. Three types of the subjects were excluded in this research: (1) who did not receive any professional intervention before six-year-old, (2) who was not studying in a general class or general class with resource classroom in junior high school, and (3) whose survey data was not valid or incomplete. The final number of subjects used in this research study is 526. Of the 526 subjects, 203 had mild disabilities, and 323 had moderate or severe disabilities; 329 subjects were male, and 197 were female. The subject count of 526 is sufficiently large and not too large for an SEM analysis (Loehlin, 1992).

\subsection{Research Procedure}

This research was to use CFA to verify the measurement models for the three latent variables, to quantify these three variables, and then to use SEM analysis to discover influential relationships among the latent variables. The analysis was performed with AMOS software, and the analysis procedure is the following:

\subsubsection{Develop a Measurement Model}

There are 647 questions in the SNELS questionnaire. Most of them are checklists and some of them are scales. For the purposes of the present research, the answers to 13 scale questions served as candidates for the observed variables in the measurement model. Next, link these candidate observed variables to the corresponding latent variables.

\subsubsection{Perform CFA}

For each latent variable, a number of iterations of CFA and model modifications were performed until the measurement model was valid. The criteria for model modification are the following: The observed variables' normality in the model is verified with the data's kurtosis and skew. If any variable data offends normality, item parceling is tried to re-organize the input data (Hau\& March, 2004); Examine and delete any observed variable that is collinear with another observed variable to make the model parsimonious (Grewal, Cote, \& Baumgartner, 2004); Examine and delete any observed variable that can link to and quantify more than one latent variable.

\subsubsection{Develop a Structural Equation Model}

After a number of iterations of SEM and model modifications, the final structural equation model is created and the influential links are quantified; the value of each link is noted as the load coefficient. The standardized load 
coefficients of the links among the three latent variables reveal the relationship among these three latent variables.

\subsection{Research Instrument}

The survey of the data used in this research was conducted by SNELS from 2008 to 2009. The SNELS team was in charge of the entire survey process, including developing the questionnaire, randomly selecting subjects, conducting the survey, verifying the survey data, and publishing the data in their data bank. SNELS is a survey organization, sponsored by the National Science Council of Taiwan. SNELS consists of 27 experts, including special educators, sociologists, survey experts, statisticians, data analysts, etc.

\section{Results}

\subsection{Measurement Model}

In the measurement model, each of the three latent variables was initially loaded with four to five observed variables. Per CFA, the three latent variables were first quantified. Then, the model modifications were performed according to the following three criteria. (1) If an observed variable's measurement weight is smaller than 0.5 or greater than 0.95 , remove the observed variable. (2) If, in the standardized residual covariance matrix, an observed variable causes a standardized residual covariance greater than 1.96, delete the observed variable. (3) If the variance of an error is negative, delete the corresponding observed variable. Table 1 shows the final result of the model modification.

After a number of iterations of CFA and model modifications, the model was finalized. In the final model, three observed variables were removed: the age at which the child received a disability certificate, the age at which the child first received special education, and the parents' satisfaction with the child's initiative in talking to others (see Table 1). In the final model, the measurement weights between the observed variables and their corresponding latent variables are between 0.62 and 0.82 , which implies that the observed variables properly defined and quantified the three latent variables (see Table 2 for details).

Table 1: Observed Variable Analysis in Structural Model

\begin{tabular}{|c|c|c|c|c|c|c|c|}
\hline Latent variable & & Observed variable & Estimate & SE & CR & $\mathbf{P}$ & $\begin{array}{l}\text { Measurement } \\
\text { weight }\end{array}$ \\
\hline \multirow[t]{5}{*}{ School Adaptation } & $\rightarrow$ & Activity participation & 1.24 & 0.093 & 13.354 & $* * *$ & .76 \\
\hline & $\rightarrow$ & Interaction with peers & 1.44 & 0.113 & 12.684 & $* * *$ & .70 \\
\hline & $\rightarrow$ & Academic performance & 1.46 & 0.114 & 12.794 & $* * *$ & .71 \\
\hline & $\rightarrow$ & Overall education & 1.27 & 0.095 & 13.358 & $* * *$ & .76 \\
\hline & $\rightarrow$ & Interaction with teacher & 1.00 & & & & .62 \\
\hline \multirow[t]{2}{*}{ Intervention Timing } & $\rightarrow$ & Identification age & 1.30 & 0.391 & 3.332 & $* * *$ & .65 \\
\hline & $\rightarrow$ & Intervention age & 1.00 & & & & .73 \\
\hline \multirow[t]{3}{*}{ Language Skills } & $\rightarrow$ & Verbal expression & 1.15 & 0.073 & 15.802 & $* * *$ & .77 \\
\hline & $\rightarrow$ & Comprehension & 1.00 & & & & .82 \\
\hline & $\rightarrow$ & Understood by stranger & 1.57 & 0.098 & 16.044 & $* * *$ & .82 \\
\hline Intervention Timing & & & 1.74 & 0.546 & 3.183 & $* * *$ & \\
\hline e5 & & & 3.98 & 0.910 & 4.375 & $* * *$ & \\
\hline e6 & & & 1.55 & 0.525 & 2.954 & .003 & \\
\hline e7 & & & 0.14 & 0.013 & 10.751 & $* * *$ & \\
\hline e8 & & & 0.11 & 0.010 & 11.347 & $* * *$ & \\
\hline e13 & & & 0.21 & 0.014 & 14.251 & $* * *$ & \\
\hline e14 & & & 0.28 & 0.021 & 13.197 & $* * *$ & \\
\hline e15 & & & 0.15 & 0.012 & 11.978 & $* * *$ & \\
\hline e17 & & & 0.14 & 0.016 & 9.084 & $* * *$ & \\
\hline e19 & & & 0.13 & 0.017 & 7.318 & $* * *$ & \\
\hline e20 & & & 0.18 & 0.021 & 8.833 & $* * *$ & \\
\hline e21 & & & 0.27 & 0.021 & 13.041 & $* * *$ & \\
\hline $\mathrm{e} 22$ & & & 0.16 & 0.013 & 11.967 & $* * *$ & \\
\hline
\end{tabular}

$* * * p<.001$ 
The composite reliabilities (CR) and Average Variance Extracted (AVE) of the latent variables, intervention timing, language skills, and school adaptation are .646 to .836 and .478 to .614 (see Table 2). According to Fornell and Larcker's (1981) suggestion, the reliabilities of the current model meet good requirement. The reliabilities of the current model imply that these ten observed variables reasonably quantify the three latent variables.

Table 2: Composite Reliability and Average Variance Extracted of Latent Variables

\begin{tabular}{lcc}
\hline Latent variable & CR & AVE \\
\hline Intervention Timing & .646 & .478 \\
Language Skills & .827 & .614 \\
School Adaptation & .836 & .507 \\
\hline
\end{tabular}

\subsection{Model Fit Test}

The indicator results for the model fit test are as follows: (1) Chi square is 54.715. (2) Chi square/df is 1.710, which is in the recommended range. This result implies that the fitting is independent of the number of samples. (3) The goodness of fit index (GFI) is .979, the adjusted goodness-of-fit-index (AGFI) is .963, and the non-normed fit index (NNFI) is .968. These three indices are above the recommended minimal value of .90. (4) The root mean square error of approximation (RMSEA) is .037 , below the recommended maximal value of .080. (5) The root mean square residual (RMR) is .024, below the recommended maximal value of .05. In summary, the final model is reliable and valid (Table 3).

Table 3: Structure Model Fit Test

\begin{tabular}{lll}
\hline Index & Recommended values & Value \\
\hline$\chi^{2}$ & the smaller, the better & 54.715 \\
$\chi^{2} / \mathrm{df}$ & $1 \sim 3$ & 1.710 \\
GFI & $\geq 0.8$ good; $\geq 0.9$ marvelous & .979 \\
AGFI & $\geq 0.8$ good; $\geq 0.9$ marvelous & .963 \\
RMSEA & $\leq 0.08$ & .037 \\
RMR & $\leq 0.5$ & .024 \\
TLI(NNFI) & $\geq 0.9$ & .968 \\
IFI & $\geq 0.9$ & .987 \\
CFI & $\geq 0.9$ & .986 \\
\hline
\end{tabular}

* according to Fornell's (1985) criteria

\subsection{Structure Parameter Test}

In the final structural model, one path-from intervention timing to school adaptation - was removed because of its $p$-value of .14 and low load coefficient of -0.09 . This result indicates that the intervention timing does not affect children's school adaptation directly or significantly. The load coefficients of the other two paths explain how intervention timing directly affects language skills $(p<.01)$ and how language skills directly affect children's school adaptation $(p<.001)$ (see Table 4 and Figure 2). Although intervention timing does not affect school adaptation directly or significantly, intervention timing does affect language skills, and language skills affect children's school adaptation. In other words, intervention timing affects a child's school adaptation through his/her language skills.

Table 4: Structure Parameter Test

\begin{tabular}{lllccccc}
\hline Path & & & Estimate & SE & CR & $\boldsymbol{P}$ & Decision \\
\hline Intervention Timing & $\rightarrow$ & Language skills & 0.22 & 0.021 & 3.10 & .002 & Supported \\
& $\rightarrow$ & School adaptation & -0.09 & 0.017 & 1.48 & .14 & No Supported \\
Language Skills & $\rightarrow$ & School adaptation & 0.22 & 0.052 & 3.91 & $* * *$ & Supported \\
\hline
\end{tabular}

$* * * p<.001$ 

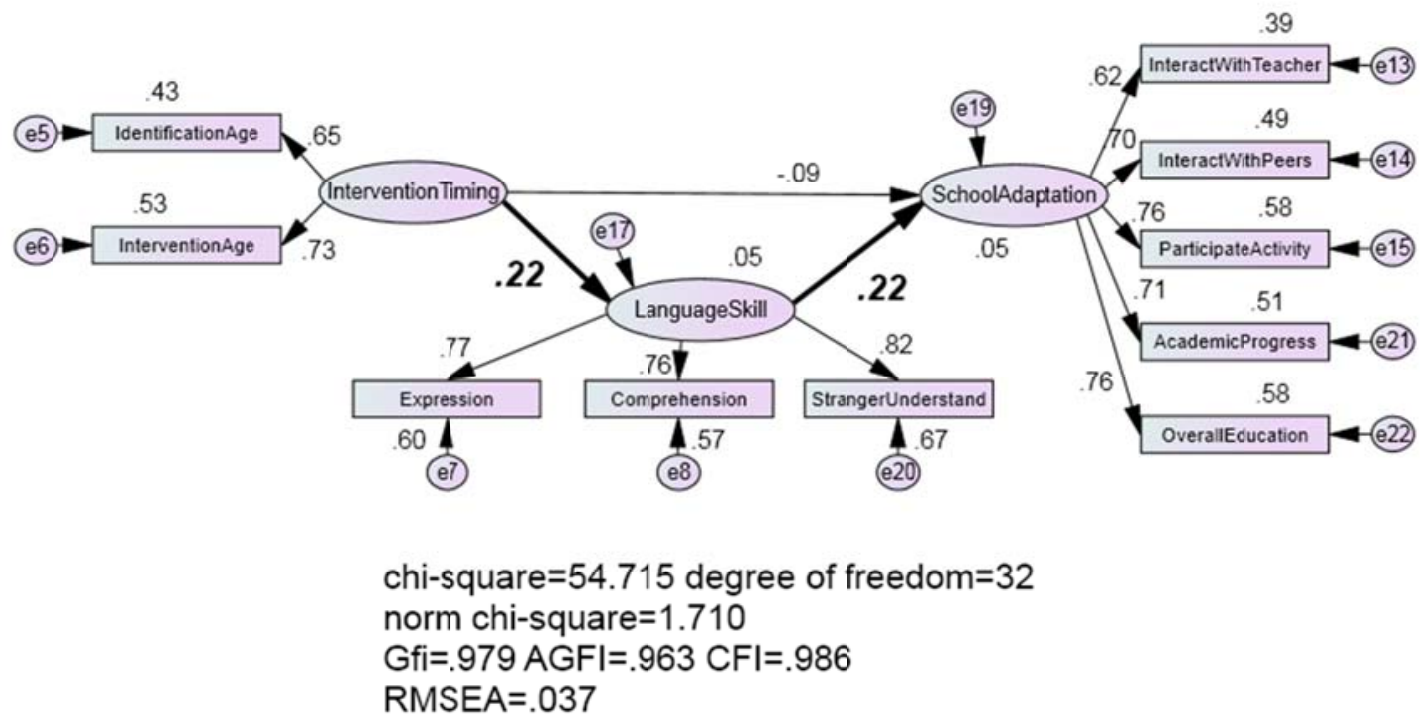

Figure 2: Intervention-Inclusion Measurement Model

\section{Discussion}

\subsection{Quantification of Three Latent Variables}

The latent variable 'school adaptation' was initially modeled as a linear combination of five observed variables: parents' satisfaction with their children's interaction with peers, interaction with teachers, activity participation, academic performance, and overall education in schools in an inclusive setting. The CFA verified that these five observed variables are correlated but are not identical one to another. The result of the CFA on the school adaptation measurement model agrees with the results of some research; for example, the first three indices of the five were also indicated in Huang (2003) and Koegel et al. (2001), and the last two indices were indicated in Oliver (2008) and Rous et al. (2010). This result provides special educators with insight regarding these indices. For example, when a special educator tries to determine how to improve the academic performance of a student with disabilities in an inclusive school setting, the teacher should examine all five indices for the student to determine the root cause of the student's academic performance problem because, according to the CFA, these five factors are correlated. For another example, if a student's parents are not satisfied with their child's interaction with peers, the parents should consider encouraging their child to begin participating in school activities and/or asking their teachers to interact with their child more frequently. Some other research indicated similar findings. For example, Koegel et al. (2001) indicated that children with disabilities often experience difficulties in participating in group activities and maintaining long-term social relationships. Participation in activities provides opportunities for individuals to interact with their social and physical surroundings.

Concerning language skills, the measurement model initially assumed that language skills were a linear combination of four observed variables: verbal expression, language comprehension, verbal expression understood by strangers, and initiating communication with others. In the CFA, the observed variable 'initiating communication with others' was not accepted as a valid variable for defining language skills because this observed variable is not correlated with the other three. This result can be explained by the fact that initiating communication with others is more related to a child's personality than to his/her language skills. The CFA shows that the variable 'verbal expression understood by strangers' differs from 'verbal expression'. For a child without disabilities, these two observed variables score the same, and one of the two should therefore be removed to avoid collinearity. However, in the present case, the CFA result indicates that verbal expression and verbal expression understood by strangers are different to some degree. This result indicates an important point: for some children with disabilities, their verbal expression, which can be understood by people who are familiar with their speaking accent and style, may not be understood by people who are not familiar with their speech. To adapt and survive in an inclusive education environment, the ability or intention to communicate with strangers is critical. Therefore, the parents, special educators, or intervention providers for children with disabilities should take the following steps: (1) when evaluating a child's language skills, 
use tests to discover if the child can communicate with strangers well, and (2) put the child in an environment where the child can practice communicating with strangers.

The intervention timing factor in the initial model was a linear combination of four observed variables: the age at which the disability was first identified, the age at which the child first received intervention, the age at which the child received a disability certificate, and the age at which the child first received special education. After iterations of CFA and model modification, the final model shows that the intervention timing factor was a linear combination of the age at which the disability was first identified and the age at which the child first received intervention. The age at which the child received a disability certificate was not accepted by the CFA as a valid index because in Taiwan, when a doctor identifies a child's disability, the doctor is mandated to report the child's disability to the local government. Then, the government will issue a disability certificate to the child. Therefore, the age at which a child first receives a disability certificate is almost identical to the age at the time of disability identification, and it therefore is a redundant variable. The other observed variable, age at first receiving special education, was also not accepted by CFA as a valid index; because most children received their first special education after the age of six, this observed variable is against normality and brings no value to the analysis. This CFA result implies that intervention timing is a combination of the time when the child's disability is identified and the time when the child starts receiving intervention. For effective intervention, there should be appropriate identification time and intervention time.

\subsection{Factors Affecting Children's Adaptation in an Inclusive School Setting}

The result of the SEM analysis reflects that if intervention timing can influence a child's school adaptation, the influence is moderated by language skills. In other words, to impact school adaptation, intervention timing must first be able to improve the children's language skills. Chen (2013) reached a similar conclusion in research on grade three children with disabilities in Taiwan, finding that the influential path is from intervention timing to language skills and then from language skills to school adaptation. Aron and Loprest (2012) concluded that the earlier the identification of disabilities in children occurs, the greater the inclusion with peers achieved.

\subsection{Language Skills Affect School Adaptation}

The present research suggests that good development of children's language skills is important to allow children with disabilities to enter into a school in an inclusive setting. Therefore, special educators and parents should closely observe and evaluate the children's language skill development from an early age and should prioritize language skills development for children with disabilities. If a child's language skills development is slower than that of most children, provide the child with language training as early as possible. If a child's language skills are much less sufficient for studying in an inclusive school, considering the child's school adaptation and psychological state, placing them in a more segregated school/classroom may be another choice.

The SEM model of the research shows that the standardized loading coefficient from language skills to school adaptation in junior high school students is $0.22(p<.01)$. In the research by Chen (2013), the SEM model's loading coefficient from language skills to school adaptation for grade one students is $0.52(p<.001)$, but the loading coefficient decreases to $0.25(p<.01)$ for grade 3 children. The influence of language skills on school adaptation is found to be the greatest when the children have just entered into elementary school. Later, the influence drops from 0.52 to 0.25 at grade three and then drops slightly to 0.22 in junior high school. These three values all reach significant influence. This result implies that children's language skills more strongly affect their adaptation in an inclusive school during their first grade year and the influence decreases in two years to a stable level. Two causes may explain this interesting phenomenon: (1) these children find ways other than verbal communication to adapt in school as they grow older, and (2) peers, teachers, and school administrators make efforts to receive these children with disabilities despite the persistence of insufficient verbal communication several years after entering elementary school. Regardless of the change of the dependency of language skills on school adaptation, this result also shows that a child's language skills still affect his/her school adaptation for many years.

\subsection{Intervention Timing Affects Language Skills}

There is a critical window of time for a child to acquire a natural language. If a child missed acquiring a natural language during this critical period, he/she would not later learn it as a native language. To have better language skills, according to the findings of this research, the children should receive intervention as early as possible.

Renshaw et al. (2009) suggested enhancing early identification and intervention efforts. Neuman (2007) indicated that the earlier the children with disabilities involved in the intervention, the more effective the intervention is. Their conclusions agree with those of this research: an earlier and appropriate intervention is effective for the intervention 
system. IDEA 1986, Special Education Act of Taiwan in 1997 (SEA), and People with Disabilities Rights Protection Act of Taiwan in 1997 (PDRPA) granted intervention programs for younger children with disabilities. The goal of these acts was to improve the development of children with disabilities by minimizing the need for special education as the children grow up (Aron \& Loprest, 2012; PDRPA, 1997; SEA, 1997). The earlier identification of disabilities enabled earlier enrollment in the intervention and promoted greater inclusion. However, the present research emphasizes that school adaptation is directly related to language skills, not intervention timing. Therefore, in addition to earlier intervention, we must also modify intervention content to emphasize the development of children's language skills.

\section{Conclusion \& Suggestion}

This research found that intervention timing impacted children' language skills and then impacted their adaptation in an inclusive school. It is suggested that a child's language skills development and adaptation in an inclusive school setting is a high priority for the intervention program. Children's language skills should be regularly evaluated and tracked to provide them with appropriate language training in a timely fashion. If, before enrolling in a school, the child's language skills are found much insufficient for an inclusive school, the parents can consider enrolling the child in a school with more segregate setting or giving the child more special language training. Therefore, a language skills evaluation system is needed to understand children's language development and to accurately assess their language performance. Using this system, children's verbal problems can be detected accurately and in a timely fashion, and thus the children can receive an appropriate and well-timed language-training program. This research also suggests that a more aggressive identification system be developed for children with disabilities so that these children can have more time to develop their language skills with help from the intervention and can have a better chance to enter and adapt well in an inclusive education environment.

Furthermore, from the CFA result, to confirm if a student is well adapted in an inclusive school, five performances should be examined at the same time, which are children's performance of interacting with peers, interacting with teachers, activity participation, and academic performance. If a child does not perform well in all of these performances, guide the child to try to improve one of the performances, such as interaction with teachers. According to the CFA result, the five performances are correlated, and improving one can make some others better. For example, if a child starts to participate in school activities more, the child will interact with their peers and teachers more frequently at the same time or some time later.

Since the data, which were recruited from SNEL database, used in this research only has intervention timing, but no intervention content, this research therefore could not take intervention content into consideration. In future research in surveying the intensity and duration of early intervention would be helpful in understanding the intervention effectiveness.

This research explored the factors impacting the adaptation of children with disabilities in inclusive schools. Future research exploring the factors that impact the general population of children' school adaptation would be beneficial. By comparing the difference between the factors that influence children with disabilities and other children, we can understand more about the mechanisms that children with disabilities use in school adaptation. Furthermore, this research explored inclusive adaptation by tracing junior high school children' intervention experience. Future research can extend the present research by conducting a follow-up study surveying the future performances of the research subjects as they enter senior high school or enter into society. This follow-up study would provide a better understanding of the influential relationships between intervention timing, language skills, school adaptation, and society adaptation.

\section{Acknowledge}

The researcher appreciates Special Needs Education Longitudinal Study of Taiwan for providing the data for this research. 


\section{References}

Akshoomoff, N., Stahmer, A. C., Corsello, C., \&Mahrer, N. E. (2013). What happens next? Follow-up from the children's toddler school program. Journal of Positive Behavior Intervention, 12(4), 245-253. http://dx.doi.org/10.1177/1098300709343724

Alquraini, T., \& Gut, D. (2012). Critical components of successful inclusion of students with severe disabilities: Literature review. International Journal of Special Education, 27(1), 42-59.

Aron, L., \& Loprest, P. (2012).Disability and the education system. The Future of Children, 22, 97-122. http://dx.doi.org/10.1353/foc.2012.0007

Baughman, B., Bruder, M. B., Coakley, T., Freyre, G., Giddings, T., Greenstein, D., Raab, M., \& Sims, J. (2010). Early childhood intervention outcome. Retrieved from http://bb8.ctdlc.org/webapps/portal/frameset.jsp?tab_id=_2_1\&url=\%2fwebapps\%2fblackboard\%2fexecute\%2f launcher\%3ftype\%3dCourse\%26id\%3d_2929_1\%26url\%3d

Brown, H. K., Ouellette-Kuntz, H., Lysaght, R., \& Burge, P. (2011). Students' behavioral intentions towards peers with disability. Journal of Applied Research in Intellectual Disabilities, 24, 322-332. http://dx.doi.org/10.1111/j.1468-3148.2010.00616.x

Chen, L. J. (2013). The factors of children with different disability levels' adaptation in inclusive elementary school settings -- An outcome-based structural equation modeling. Taiwan: NTTU Educational Research Journal, in press.

Coutinho, M. J., Oswald, D. P., \& Best, A. M. (2006). Differences in outcomes for female and male students in special education. Career Development for Exceptional Individuals, 29(1), 48-59.

Del Prette, Z. A. P., Del Prette, A., \& De Oliveira, L. A.(2012). Role of social performance in predicting learning problems: Prediction of risk using logistic regression analysis. School Psychology International, 33(6), 615-630. http://dx.doi.org/10.1177/0020715211430373

Early Childhood Outcomes Center (2010). ECO COSF 101-What is a functional outcomes. Retrieved from http://www.fpg.unc.edu/ eco/assets/pdfs/Functional_outcomesHO.pdf

Fornell, C., \& Larcker, D. F. (1981). Evaluating structural equation models with unobservable variables and measurement error. Journal of Marketing Research, 18(1), 39-50. http://dx.doi.org/10.2307/3151312

Grewal, R., Cote, J. A., \& Baumgartner, H. (2004). Multicollinearity and measurement error in structural equation models: Implications for theory testing. Marketing Science, 23(4), 519-529. http://dx.doi.org/10.1287/mksc. 1040.0070

Hau, K. T., \& March, H. W. (2004). The use of item parcels in structural equation modeling: Non-normal data and small sample sizes. British Journal of Mathematical Psychology, 57, 327-351. http://dx.doi.org/10.1111/j.2044-8317.2004.tb00142.x

Huang, Z. Z. (2003). The effectiveness of interpersonal problem solving training for students with disabilities in inclusive setting. Taiwan: Educational Research Journal, 11, 189-212.

Kasprzak, C., \& Rooney, R. (2008). Using the child outcomes summary form. In Early Childhood Outcomes Center website. Retrieved from http://www.nectac.org/\%7Estream/eval/cosftraining1/

Koegel, L. K., Koegel, R. L., Frea, W. D., \& Fredeen, R. M. (2001). Identifying early intervention targets for children with autism in inclusive school settings. Behavior Modification, 25(5), 745-761. http://dx.doi.org/10.1177/0145445501255005

Loehlin, J. C. (1992). Latent variable models: An introduction to factor, path, and structural analysis(4th ed.). NJ: Lawrence Erlbaum.

Neuman, S. B. (2007). Changing the odds. Early Intervention at Every Age, 65(2), 16-21.

NICHD Early Child Care Research Network (2005). Early child care and children's development in the primary grades: Follow-up results from the NICHD study of early child care. American Educational Journal, 42(3), 537-570.

Oliver, L. A. (2008). Be prepared: Tips for transitioning into early childhood education. The Exceptional Parent, 38(9), 20-22. 
People with Disabilities Rights Protection Act in 1997 (PDRPA).

Rabren, K., \& Johnson, C. (2010). Postschool outcome data collection programs: Examples from two states. Career Development for Exceptional Individuals, 33(1), 52-63.

Renshaw, T. L., Eklund, K., Dowdy, E., Jimerson, S. R., Hart, S. R., Earhart, J., \& Jones, C. N. (2009). Examining the relationship between scores on the behavioral and emotional screening system and student academic, behavioral, and engagement outcomes: An investigation of concurrent validity in elementary school. The California School Psychologist, 14, 94-104.

Rossetti, Z. S. (2011). That's how we do it: Friendship work between high school students with and without autism or developmental disability. Research \& Practice for Person with Severe Disabilities, 36, 23-33. http://dx.doi.org/10.2511/rpsd.36.1-2.23

Rous, B., Hallam, R., McCormick, K., \& Cox, M. (2010). Practices that support the transition to public preschool programs: Results from a national survey. Early Childhood Research Quarterly, 25, 17-32. http://dx.doi.org/10.1016/j.ecresq.2009.09.001

Shonkoff, J. P., \& Meisels, S. J. (2002). Handbook of early childhood intervention. NY: Cambridge.

SNELS (2013). Special Needs Education Longitudinal Study of Taiwan. Retrieved from http://snels.cycu.edu.tw/

Special Education Act of Taiwan in 1997 (SEA).

Stahmer, A. C., Carter, C., Baker, M., \& Miwa, K. (2003). Parent perspectives on their toddlers' development: Comparison of regular and inclusion childcare. Early Child Development and Care, 173(5), 477-488. http://dx.doi.org/10.1080/0300443032000088267 